\title{
Material Evaluation through Class Observation: A Way of Small-scale Adaptation
}

\author{
Anupam Biswas, Muhammad Jakaria Faisal
}

Department of English, Dhaka Commerce College, Mirpur-2, Dhaka, Bangladesh

\begin{abstract}
Teaching materials have significant impact on learners' learning. To facilitate English teaching and learning materials are abundant but teachers should evaluate the efficiency of those materials by taking serious principles into consideration during adaptation. The evaluation conducted here is on a small scale. The class that has been observed focuses on writing skills-basically on identifying common errors in the writings of EAP learners. It was a course on Basic English (ENG 101) intended for the students of first semester in BA (Honours). Therefore, the learners' age range is 18-22 and their language proficiency is supposedly of intermediate level. Interview of the course instructor revealed that the learners like communicative approaches more than learning bare grammar rules and structures. The materials used in that class was adapted from The Advancing Writer-Book / by Karen L. Greenberg, Peter Rodinone and Harvey Wienore. The aim of this evaluation is to scrutinize the suitability and effectiveness of the above materials for the target learners. At the end, some changes, modifications, and improvisations for the materials have been recommended.
\end{abstract}

Keywords-Authenticity, Content, Evaluation, Material, Process.

\section{INTRODUCTION}

Materials evaluation through class observation: A way of small-scale adaptation

The success of teaching is measured to a great extent by the success of learning. The selection and use of teaching materials bridges these two arenas. Choosing a suitable material and using it effectively can facilitate teaching and learning. Wrong choice of material, on the other hand, can turn teaching and learning into an unpleasant experience. Even the right choice of material cannot help if the teacher does not have the necessary skills to implement it and try to make the best of it. To avoid this unpleasant situation, conducting materials evaluation is worthwhile. It can help a teacher not only to select materials suitable for learners and judge if it has achieved its purposes after implementation, but it can also help to adapt, modify and improvise available materials and also to develop new materials. Classobservation can prove to be very much effective in evaluating materials. Before going to that point, let us have some idea about what we understand by materials and materials evaluation and what purposes they can serve.

\section{LITERATURE REVIEW}

According to Tomlinson (2001), “"Materials' include anything which can be used to facilitate the learning of a language". They can vary in nature such as being "linguistic, visual, auditory or kinaesthetic" that can range from printed materials to non-print ones. Tomlinson identifies materials "represented in print, through live performance or display, or on cassette, CD-ROM, DVD or the internet" (p. 66). In the words of Richards (2001), materials can be in the form of a textbook, or it can be prepared institutionally while sometimes it can also be produced by the teacher himself/herself. He distinguishes four types of materials that can be sorted into two broader types:

\section{Instructional/commercial/created materials-}

a) printed materials such as books, workbooks, worksheets, or readers;

b) nonprint materials such as cassette or audio materials, videos, or computer-based materials;

c) materials that comprise both print and nonprint sources such as self-access materials and materials on the internet

\section{Authentic materials-}

d) materials not designed for instructional use such as magazines, newspapers, and TV materials (p. 251)

To determine the suitability of materials, evaluation plays an important role. Tomlinson (2003) defines materials evaluation as "a procedure that involves measuring the 
value (or potential value) of a set of learning materials". It is also capable of "making judgments about the effect of the materials on the people using them" (p. 15). He provides three types of evaluation of materials- pre-use, whilst-use and post-use. However, different procedures should be followed for evaluating different types of materials.

The evaluation conducted here is on a small scale. It will be based on a single observation on the implementation of teaching materials in an EAP classroom. The class that has been observed focused on writing skills- basically on identifying common errors in the writings of EAP learners. It was a course on Basic English (ENG 101) intended for the students of first semester in BA (Honours). Therefore, the learners' language proficiency is supposedly of intermediate level. The age range of the learners is $18-22$. From the interview with the instructor before the class, I came to know that the learners liked communicative approaches more than learning bare grammar rules and structures. The materials used in that class were on 'fragments'. It was adapted from The Advancing WriterBook 1 by Karen L. Greenberg, Peter Rodinone and Harvey Wienore. The aim of this evaluation is to scrutinize the suitability and effectiveness of the above materials for the target learners. At the end, some changes, modifications, and improvisations for the materials have been recommended and also ways of using the materials more effectively in class have been suggested. Before proceeding further, it needs to be acknowledged that the three steps of materials evaluation provided by Breen (1989) have been adopted to conduct the study (See Appendix 1). The checklists of evaluation criteria provided by Cunningsworth (1984) (See Appendix 3 and 4) have also been consulted to devise a new checklist to evaluate the above materials. Thus an individual framework of evaluation suitable for those particular materials has been set up because "the framework used [for the evaluation of materials] must be determined by the reasons, objectives and circumstances of the evaluation" (Tomlinson, 1999, p. 11).

\section{MATERIALS AS WORKPLAN}

Breen's three phases- materials-as-workplan, materialsin-process, and Outcomes from materials- parallel with Tomlinson's (2003) three types of evaluation. They are parallel to the pre-use evaluation, whilst-use evaluation and post-use evaluation. Similar to Breen's first phase, materials-as-workplan, pre-use evaluation "involves making predictions about the potential value of materials for their users" (p. 23). It evaluates the theoretical value or the 'construct validity' of the materials. It examines the materials 'as they stand' without referring to their 'actual use in the classroom'. At this point, a new evaluation checklist supporting on two other checklists of evaluation provided by Cunningsworth (1984), and using Moore's (1980) evaluation questions (See Appendix-2) has been devised, to examine how suitable the materials are for the target learners:

\section{EVALUATION CHECKLIST}

- Do the materials have any clearly defined aim?

- Is the amount of language input presented in the materials sufficient?

- How far can the materials arouse learner interest?

- How far are the materials relevant to learner's needs and interests?

- Is it challenging?

- Is the material culturally appropriate for the learners?

- Are the activities varied?

- Are the activities sufficiently controlled?

- Is the appearance of the material attractive?

- Does it involve the learners in the learning process?

a) Purpose- The materials used in the class that that has been observed states their aims clearly on the first page: "Before you begin this chapter. The aims of this chapter on fragments. Learning how to craft clear, complete sentences". Thus it operates as an example of fragments at the same time.

b) Content- The proportion of language given and learner task in the materials is balanced. There are sufficient examples and explanations to help students with the tasks. The instructions are clear and accompanied by examples to make them clearer to the learners.

c) Interest- The interview with the instructor before the class reveals that this particular group of learners is very much fond of communicative approaches. As we can see, the materials used in that class state bare grammar rules and structures directly. So, we may assume that these materials do not stimulate learner interests.

d) Authenticity- Fragments are very common mistakes in the writings of ESL learners. As we know that fragments are accepted in spoken language, but they are not allowed in written language. Learners often are not aware of this distinction and use different kinds of fragments in their 
writings not knowing that they are fragments. They are not aware of the fact that written language consists of more formal structure of sentences. From that point of view, the tasks in the materials are very useful for the learners of EAP course. The materials include tasks such as identifying fragments in writing, and the reasons why fragments occur by comparing between spoken and written language. The tasks are meaningful in the sense that they are supposed to help students avoid fragments and 'craft complete sentences'. The tasks are challenging too, because the learners have learned the features that make a complete sentence. Now they are going to learn how absence of any of those features leaves a sentence incomplete. Thus, in terms of Krashen's ' $i+1$ ' model, it is one step ahead from the present proficiency level of the learners.

e) Difficulty/Ease- The tasks and activities in the materials do not demand too much or too less from the learners for their present proficiency level. Therefore, it is not demotivating in terms of its level of difficulty or ease.

f) Cultural context- The materials are not appropriate in Bangladeshi cultural context. Topics such as Santa Fe Trail, or a giant octopus, or Halloween have nothing to do with the students of Bangladeshi cultural background. On top of it, dealing with a topic like Halloween makes the materials culture-specific that might not be acceptable to the learners. Nevertheless, one of the activities deals with the harmful effects of drug addiction that has some universal appeal.

g) Variety- The activities in the materials do not have any variety. Same kind of activities has been repeated. Though there are group works, they do not have different activities. It will not be an exaggeration to call the activities monotonous.

h) Control- The activities in the material are controlled more than is necessary. It teaches one rule at a time and set the learners immediately to apply that rule in exercises. The learners are not left with many choices or options.

i) Appearance- The appearance of the materials is not at all attractive. It does not have any illustrations or pictures in it. Activities are plainly laid out without any novelty or variety.

j) Stimuli- The activities in the materials do not involve the learners in the learning process itself. They require that the learners memorize the grammatical rules of fragments and apply them in exercises.

\section{MATERIALS IN PROCESS}

This phase measures the empirical value of the materials by generating information about the ways in which learners and teachers actually use and respond to materials, thus providing indicators whether the materials are 'successful' or not. This phase is parallel to Tomlinson's (2003) Whilstuse evaluation. It "involves measuring the value of materials whilst using them or whilst observing them to be used" (p. 24). Tomlinson (1998) articulates some principles too to be used as a basis of materials evaluation through his Second Language Acquisition Research (SLA) (See Appendix-6). These principles have been assimilated with some other principles postulated by the researchers to be used as a measure-scale of the material that was observed while it was being used in the class. Only those principles have been dealt in here that are appropriate for and applicable to that particular material:

1. Materials should achieve impact- In order to achieve impact, materials should have novelty, variety, attractive presentation and appealing content. The material on fragment does not have any of these qualities. Except one or two, the topics are neither unusual, nor usual; rather they are alien to the learners. There is no illustration. The activities perform the task of drilling the same rules again and again. The instructor did not add anything new to bring variety to the activities. She used the material as it was though she had the freedom of modifying the material. The presentation of the material is dull. The teacher did not use any photographs to make it attractive. The topics of the activities used in the class were 'Halloween' and 'Octopus' that are not relevant to the interests of the target learners. The teacher did not offer any choices though she knew her students very well. For example, she knew that the students liked communicative approaches.

2. Materials should help learners to feel at ease- The learners can in no way relate the topics of the material to their own culture. Most of the students did not know what 'Halloween' was. The instruction given in the material uses passive voice and the language of instruction is very formal. No attempt from the part of the teacher to rephrase the language or introduce new topics was found.

3. Materials should help learners to develop confidenceThe teacher made the learners do simple drills. She did not encourage learners to use their imaginative power or analytical abilities. 
4. Materials should require and facilitate learner selfinvestment- There is no chance for the learners to learn through self-discovery in this material. They got everything readymade before them. The topics were not very interesting or stimulating. The teacher did not make any attempt to get the students to "respond to it globally and affectively and then to help them to analyse a particular linguistic feature of it in order to make discoveries for themselves" (Tomlinson, 1998, p. 11).

5. Materials should expose the learners to language in authentic use- The input in the material is not authentic in that it is not rich and varied. The language of the input is very formal and does not vary in style. Yet, the tone of the language is more or less conversational.

6. Materials should take into account that the positive effects of instructions are usually delayed- The teacher was forcing the students towards premature production of the instructed features. For example, she quickly read out a new rule of correcting fragments to the students and immediately set the learners to do the activities. Though the teacher was going to each student and monitoring the progress while they were doing the activities, most of the students failed because of the pace of the lesson. She did not give them any time to grasp the rule well at first. Throughout the whole class, the pace was too fast for the students to follow.

7. Materials should permit a silent period at the beginning of instruction- The teacher started the class with the homework assigned in the previous class. The students were not given any scope to prepare mentally for the lesson. The teacher did not provide any picture or story or anecdote so that the students would get time to think.

8. Materials should not rely too much on controlled practice- The activities in the material are rigorously emphasize on controlled practice. Referring to Ellis (1990), Tomlinson argues that "controlled practice appears to have a little long term effect on the accuracy with which new structures are performed" (p. 192) and that doing drills is a waste of time. If the students are not provided lots of options, they are likely to lose interests in the activities. The teacher was not found to be very much enthusiastic in figuring out ways to make the activities interesting to the learners.

9. Materials should encourage students to practice their noticing power- As it has been said earlier, that the material presents grammatical rules barely. The teacher did not apply any strategy that helped the students use their noticing power. They might not know the technical terms such as 'fragments', but they might have been able to recognize an incomplete sentence if they were introduced to a group of fragmented sentences.

10. Materials should be designed keeping in mind students' socio-cultural and economic background- It has been said before that the topics of the materials are not relevant to the learners' socio-cultural background. Moreover, they are culture-specific in some cases. Pulverness (2003) points out the problem of culturespecific materials where Cunningsworth (1984) states that-

A limitation of the culture-specific coursebook is that it will only be of relevance to students who understand the cultural background in which it is set... The [learner's] time would be better spent learning the language rather than the structuring of the social world in which the learner is never likely to find himself. (p. 61-62) Thus, the learners from a different culture may feel themselves marginalized by the materials depicting a different culture. However, this is where the teacher's role comes into play. It was the teacher who could have made it more dynamic. Instead, she did not try some other topics that were culturally more relevant to the learners.

11. Materials should provide opportunities for learner to learner interaction- This is a point where the teacher played a positive role. She called the students to the board one by one and made them write one answer each. She took these samples of learner output to use as further input. For example, if one student wrote a wrong answer on the board, she would invite other students to identify the mistakes and come up with the right form. Nevertheless, she did not assign them any group work or pair-work that could have facilitated interaction. There was only teacher-learner interaction, but no learner-learner interaction. Here, the teacher failed the course description which claims that "The approach at all times will be communicative and 
interactive and will involve individual, pair and group work" (See Apeendix-5).

\section{OUTCOMES FROM MATERIALS}

This phase measure the relative achievements of the learners. This is similar to Tomlinson's (2003) post-use evaluation. He considers it as the most valuable type of evaluation. As it has been done on a small-scale, this evaluation is limited to measuring the effect of the material on learner motivation, impact and instant learning. As for instant learning, the students failed in most of the cases to produce correct forms because of premature production. However, as far as it is concerned with the motivation and impact, a different way was adopted. After the class was over, students were asked some general questions to that received the following responses-

Q- How do you like the lesson?

- "Same type of exercises again and again"

- "Memorizing grammar rules is difficult and boring"

- "I really don't like these grammar classes"

- "Grammar needs common sense, not rules"

The above responses imply that the material could not achieve impact or motivate the learners by growing their interests only because it presents grammar rules in a way that the learners become conscious and warned. To some extent, it is threatening too.

\section{RECOMMENDATIONS}

The interview with the teacher after the class reveals that she had the necessary freedom to adapt the material in her own ways that she thought was necessary. Here are some possible ways through which she could have adapted the material-

1. New activities could have been added to break the monotony (e. g. information gap, multiple choices, true/false, and group work/pair-work).

2. Other relevant topics could have been introduced. For example, more culturally relevant topics such as 'PohelaBoishakh' could have replaced 'Halloween'.

3. Some pictures of Halloween could have been shown and a description could have been given.

4. Some samples of fragments could have been presented at the beginning to make the students use their existing proficiency before introducing the topic. Thus the rules for correcting and avoiding fragments could have been camouflaged or hidden from the clear view of the learners. Bare grammatical rules make the students aware that they are learning something which most of them do not like.

However, when the teacher as asked why she did not make any attempt to adapt the material, she said that teaching grammatical rules through communicative approach did nor have a long-term effect. The students enjoyed classes where communicative approaches were followed, but they often failed to reproduce the grammar rules in the tests given to them. This was the reason why she and other teachers make the students memorize grammar rules. Despite the fact, it should be remembered that forcing the students in learning something is not a good idea. In order to achieve a long term effect, materials must incite some amount interest into the learner and motivate them. They also have to be relevant to the learners' needs and interests and consider their cultural background. Internationally or globally produced materials often deal with topics of general interests. It is the users who can make them relevant to the learners' needs through changing, modifying, improvising and finally adapting the materials.

\section{REFERENCES}

[1] Breen, M. (1989). The evaluation cycle for language learning tasks. In P. Rea-Dickins and K. Germaine (Eds), Evaluation. Oxford: Oxford University Press.

[2] Cunningsworth, A. (1984). Evaluating and Selecting EFL Teaching materials. Great Britain: Biddles Ltd.

[3] Moore, J. (1980). Materials Development: a case study. In English for Specific Purposes: An International Seminar. 1722. April, 1977. London: British Council.

[4] Tomlinson, B. (Ed.). (1998). Materials Development in Language Teaching. Cambridge: Cambridge University Press.

[5] Tomlinson, B. (1999). Developing criteria for evaluating L2 materials. IATEFL Issues, February-March, 147, 10-13

[6] Tomlinson, B. (2001). Materials Development. In Carter, R. and Nunan, D.(Eds.), The Cambridge Guide to Teaching English to Speakers of Other Languages. Cambridge: Cambridge University Press.

[7] Tomlinson, B. (2003). Developing Materials for Language Teaching. Continuum. 


\section{Appendices}

Appendix-1: Breen's (1989) three phases of material evaluation

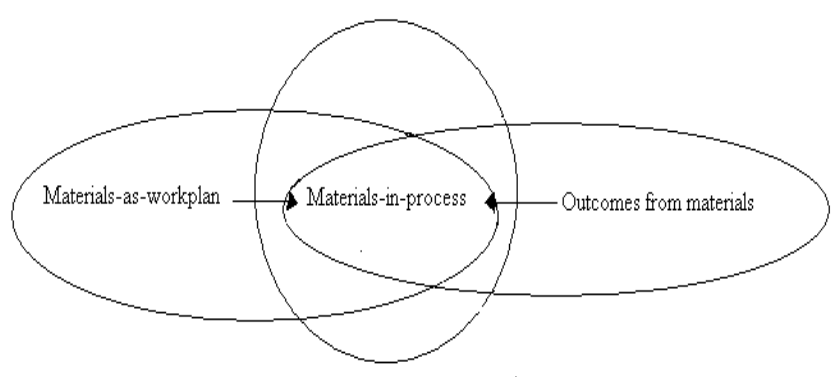

1. Breen's (1989) three phases of evaluation

Appendix-2: Evaluation questions of Moore (1980)

\begin{tabular}{|ll}
\hline PURPOSE & Is the purpose clearly defined? \\
TYPE & $\begin{array}{l}\text { Does the type of exercise effectively and } \\
\text { economically accomplish the purpose? }\end{array}$ \\
CONTENT & Is the ratio of language given/learner task \\
& economic? \\
& Are instructions to learners clear? \\
INTEREST & Is it interesting? \\
AUTHENTICITY Is it a meaningful task? \\
DIFFICULTY & Does it contain distracting difficulties?
\end{tabular}

\section{Appendix-3: Cunningsworth's (1984) 'checklist of} evaluation criteria'-1

\section{Presentation and practice of grammar items}

Comment on the presentation of new structures (grammar items).

How are new structures presented? To what extent is the presentation:

related to what has been previously learned?

meaningful (in context)?

systematic?

representative of the underlying grammar rule?

appropriate to the given context?

relevant to learners' needs and interests?

Comment on practice actidities for new structures. Are they:

- $\quad$ adequate in number?

varied?

meaningful?

appropriate to the given context?

relevant to learners' needs and interests?

sufficiently controlled?

\section{Appendix-4: Cunningworth's (1984) 'checklist of}

evaluation criteria'-2

\section{Chapter 7 Motivation and the learner}

Does the material have variety and pace?

Is the subject matter of reading texts, listening passages etc. likely to be of genuine interest to the learners, taking into account their age, social background, their learning objectives and the composition of the class?

Does the material have an attractive appearance (visuals, layout, typography etc.)?

Do the activities in the material encourage the personal involvement of the learners in the learning process (e. g. by talking about themselves or finding out about each other)?

If material is culture-specific, will this be acceptable to the learners?

Is there a competitive or problem-solving element in the learning activities? 